\title{
Sedation and anaesthesia for cardiac catheterisation
}

\author{
A Schure \\ Department of Anaesthesiology, Critical Care \& Pain Medicine, Boston Children's Hospital, United States of America \\ Corresponding author, email: annette.schure@childrens.harvard.edu
}

\section{Summary}

Since the introduction of cardiac catheterisation for Paediatric Cardiology in 1947, the subspecialty has seen dramatic changes. The advancement of non-invasive imaging techniques such as echocardiography, CT and cardiac MRI has shifted the focus for paediatric cardiac catheterisations from a primarily diagnostic tool (to define anatomy, assess haemodynamics and calculate shunts) to an important treatment option for various congenital heart defects.'

Keywords: sedation, anaesthesia, cardiac catheterisation

According to the IMPACT (Improving Paediatric and Adult Congenital Treatment) registry, a multicenter national database for paediatric and adult congenital heart disease (CHD) patients undergoing diagnostic and interventional catheterisation, from 2011-2013, about 2/3 of the reported cases involved one or more interventions, 35\% were classified as diagnostic only. Adverse events occurred in 10-11\%. Anaesthesiologists were taking care of the patients in $84 \%$ of the diagnostic procedures and $87.8 \%$ of the interventional catheterisations. ${ }^{2}$ This a major evolution from the old sedation protocols, often based on a "lytic cocktail" (i.e. intramuscular injection of meperidine, promethazine and chlorpromazine) which had been used for many decades; and most likely caused by increasing complexity of the CHD patients, provider preference, need for absolute immobility, prolonged durations and new hospital or national sedation policies.

The anaesthesiologist who is assigned to the paediatric cardiac cath lab is facing multiple challenges:

\section{Challenge 1: The environment}

- Off-site location: In many institutions the paediatric cardiac catheterisation suite (PCCS) is located far away from the operating rooms, intensive care units, anaesthesia supply areas and support resources. Additional equipment (e.g. difficult airway cart) and help will be significantly delayed. Anticipation of potential needs and early call for help is of vital importance.

- Crowded room and limited space: The monitor and camera systems are very bulky and occupy a substantial amount of space in the room. Additional cardiology equipment (TEE machine, defibrillator, etc.) is often required and positioned close to the patient, further restricting any available room for anaesthesia equipment. Access to the patient is very limited. Camera rotations and table movements can easily cause accidental disconnections, extubations or removal of intravenous access.

- Constant threats: radiation exposure, hypothermia, limited mobility, poor visibility: The anaesthesiologist is constantly exposed to radiation during the catheterisation and must wear protective lead, maintain adequate distance from the cameras and hide behind barriers, leading to poor mobility, fatigue and further limiting the ability to access the patient. Catheterisation suites are usually kept cold to protect the expensive equipment from overheating and require creative warming strategies to keep the patients normothermic. For most of the case the lights are switched off and visual monitoring of the patient, the anaesthesia equipment, medications labels, etc. becomes challenging.

\section{Challenge 2: Safety}

Paediatric cardiac catheterisation suites are one of the most dangerous places for anaesthesiologists to work, not only because of the constant threats to their own safety (radiation exposure, injury from rotating cameras, etc.), but also because of the high risk for adverse events. In the POCA (Paediatric Perioperative Cardiac Arrest) registry $17 \%$ of the reported cardiac arrests occurred in the PCCS. ${ }^{3}$ The IMPACT database reports adverse events in $10-11 \%$ of all catheterisations. ${ }^{2}$ Adverse events can be classified into minor and major events, i.e. life-threatening, requiring immediate interventions or resulting in a significant permanent lesion (cardiac arrest, tamponade, embolised device, stroke, etc.). Major events occur in $1-2 \%$ of cases. The list of potential complications is long and comprehensive (Table I). ${ }^{1}$

Several recent studies have tried to identify high-risk patients and procedures in order to develop risk stratification scores to facilitate resource allocation and outcome comparisons between institutions. ${ }^{4-6}$ Major adverse events occurred more often in neonates (4.2-4.7\%) than in children and adolescents (0.7-0.8\%). Table II presents a list of high-risk patients and procedures which has been published in an expert consensus statement by the SCAI, CCAS and SPA. ${ }^{7}$ 
Table I: Complications in the paediatric cardiac catheterisation suite (modified ${ }^{1}$

\begin{tabular}{|c|c|}
\hline \multicolumn{2}{|c|}{$\begin{array}{l}\text { Vascular complications: } \\
\text { - Arterial thrombosis and occlusion } \\
\text { - Venous thrombosis and occlusion } \\
\text { - Vessel rupture, perforation and dissection } \\
\text { - Cardiac perforation and tamponade }\end{array}$} \\
\hline \multicolumn{2}{|c|}{$\begin{array}{l}\text { Damage or dysfunction of a valve } \\
\text { - Temporary regurgitation caused by wires } \\
\text { - Permanent damage: acute insufficiency }\end{array}$} \\
\hline \multirow{2}{*}{\multicolumn{2}{|c|}{$\begin{array}{l}\text { Arrhythmias } \\
\text { - Catheter induced complete heart block } \\
\text { - Atrial tachyarrhythmias } \\
\text { - Ventricular tachycardia or fibrillation } \\
\text { Desaturation } \\
\text { - Respiratory: pulmonary edema, hemoptysis } \\
\text { - Circulatory: increased shunting, PVR } \\
\text { - Mechanical: TEE probe, pneumothorax, etc. }\end{array}$}} \\
\hline & \\
\hline \multicolumn{2}{|c|}{$\begin{array}{l}\text { Table Il: High risk patients and procedures for anaesthesia in the } \\
\text { paediatric cardiac catheterisation suite }{ }^{7}\end{array}$} \\
\hline $\begin{array}{l}\text { Williams-Beuren syndrome } \\
\text { Hypertrophic cardiomyopathy } \\
\text { Single ventricle physiology } \\
\text { Aortic valve stenosis } \\
\text { Mitral valve stenosis } \\
\text { Pulmonary hypertension }\end{array}$ & $\begin{array}{l}\text { Pulmonary vein dilation } \\
\text { VSD device closure } \\
\text { Balloon atrial septostomy } \\
\text { for newborns with single } \\
\text { ventricles and left AV hypoplasia, } \\
\text { etc. } \\
\text { s/p heart transplant }\end{array}$ \\
\hline
\end{tabular}

\section{Challenge 3: Anaesthesia}

No anaesthesia technique or medication combination is perfect or appropriate for all patients. The most important concept for successful sedation or anaesthesia in the PCCS is a thorough understanding of the underlying pathophysiology and the potential responses to sedation, positive pressure ventilation, vasodilation and impaired contractility. During the preoperative evaluation, the anaesthesiologist should address important questions to assess the heamodynamic status: How does the blood flow through the circulations? How is the baseline ventricular function? How reactive is the pulmonary vasculature? Is there a fixed or dynamic outflow obstruction? How well will hypoxia or hyperoxia be tolerated? What is the most likely response to sympathetic stimulation or vasodilation? Myocardial depression? And finally, what situations can lead to cardiovascular collapse, and how can they be avoided or treated?' For a well-designed individualised anaesthesia plan another set of questions is also crucial:

1. What are the indications for the catheterisation? ${ }^{8}$

a. Haemodynamic assessment, presurgical evaluation, surveillance?

b. What specific questions need to be answered?

c. What interventions are planned? Where?

2. What are the most likely complications? How are they treated?

3. Does the cardiology team need special access? Why?

4. What is the best anaesthesia technique? Sedation or general anaesthesia? LMA or ETT?

5. Is endocarditis prophylaxis indicated?

6. Where will the patient recover after the procedure? Recovery room or ICU?

\section{Blood loss}

Embolisation

- Device, balloon, thrombus/dislodged items

- Air embolism

Contrast toxicity

- Acute reactions

- Delayed reactions

- Nephrotoxicity

Neurological events

- Central NS: embolic strokes, ischaemic encephalopathy

- Peripheral NS: brachial plexus injury

Hypothermia

Endocarditis
Many cardiac patients have high levels of anxiety or behavioural problems and will benefit from a premedication. Midazolam alone or in combination with ketamine is frequently used. Peripheral IV access can be challenging. If anticipated, additional equipment (vein finder, ultrasound, etc.) and help should be available. Patient status, the potential duration of the procedure, need for immobility, risk of complications and provider experience are important considerations for the choice of anaesthesia and airway management. To minimise the risk for post-procedural bleeding and haematoma formation, smooth emergence and extubation are desirable but not always easy to achieve. $^{9}$

\section{Challenge 4: Coordination and communication}

Nowadays, cardiac catheterisation is just one of the pieces in the cardiology imaging puzzle. Anaesthesiologists are often asked to coordinate anaesthesia and sedation for additional procedures like echo, CT or cardiac MRIs, which can be a logistical nightmare. The pro/con debate over the benefits of this "diagnostic marathon" under anaesthesia is ongoing: Is one 8-hour long anaesthetic (echo + cardiac MRI + Cath) better than three short ones? What is best for the families? For the patients? For the hospital?

The increasing complexity of the cardiac patients as well as the interventional procedures requires good communication between all members of the periprocedural care team: cardiologists, interventionalists, anaesthesiologist, nursing staff, radiology technicians and intensivists. Pre-procedural huddles and the use of pre-, intra- and post-procedural checklists have been proposed.

\section{Challenge 5: Innovations and new technologies}

Innovative techniques and new equipment, frequently adapted from the adult world, are constantly introduced into PCCS. There is always a learning curve for the team, and these procedures are often prolonged, involve multiple sheath changes and may require additional (space-occupying) equipment and staff. Here are some examples:

- Intracardiac echocardiography (ICE) 
- 3D-rotational angiography (3DRA, the "spin"): 3Dreconstruction of angiography images to facilitate dilations and stent placements, requires good coordination with anaesthesia provider, associated with a high risk of accidental disconnections. ${ }^{10}$

- Multimodal 3D image integration: integrated 3D images from 3DRA, CT and MRI overlaid onto live fluoroscopy to guide interventions (road mapping). ${ }^{11}$

- Percutaneous pulmonary and aortic valve placements: new devices and smaller delivery systems.

- PDA device closure in premature and low weight infants. ${ }^{12}$

- Stenting of vertical vein in newborns with total anomalous pulmonary venous return.

- RVOT stenting in patients with Tetralogy of Fallot.

- Ductal stenting for duct dependent lesions.

- Hybrid procedures: combined interventional and surgical approaches:

- HLHS: ductal stenting and surgical bilateral PA banding

- VSD device closure: wire insertion via right ventriculotomy

\section{- MRI-guided paediatric cardiac catheterisation. ${ }^{13}$}

\section{Conclusion}

Anaesthesia in the paediatric cardiac catheterisation suite can be very challenging. A thorough preoperative evaluation and assessment are critical as well as good coordination and communication with the periprocedural care team. Complex procedures and high-risk patients will require providers with extensive cardiac experience and training.

\section{Suggested reading:}

- Rawlinson E, Foreshaw N. Interventional cardiology. In: Coté CJ, Lerman J, Anderson B, editors. A practice of anaesthesia for infants and children. 6th ed. Philadelphia: Elsevier; 2019. Chapter 22. p. 520-33.

- Vincent RN, Moore J, Beekman RH, et al. Procedural characteristics and adverse events in diagnostic and interventional catheterisations in paediatric and adult CHD: initial report from the IMPACT Registry. Cardiol Young. 2016;26:70-8

- Odegard KC, Vincent R, Baijal R, et al. SCAI/CCAS/SPA expert consensus statement for anaesthesia and sedation practice: Recommendations for patients undergoing diagnostic and therapeutic procedures in the paediatric and congenital cardiac catheterisation laboratory. Catheter Cardiovasc Interv. 2016;88:912-22.

- Feltes TF, Bacha E, Beekman RH III, et al. Indications for cardiac catheterisation and intervention in paediatric cardiac disease: a scientific statement from the American Heart Association. Circulation. 2011;123:2607-52.

\section{References:}

1. Rawlinson E, Foreshaw N. Interventional cardiology. In: Coté CJ, Lerman J Anderson BJ, editors. A practice of anaesthesia for infants and children. 6th ed. Philadelphia: Elsevier; 2019. p. 520-33.

2. Vincent RN, Moore J, Beekman RH, et al. Procedural characteristics and adverse events in diagnostic and interventional catheterisations in paediatric and adult CHD: initial report from the IMPACT Registry. Cardiol Young. 2016;26:70-8. https://doi.org/10.1017/S1047951114002637.

3. Ramamoorthy C, Haberkern CM, Bhananker SM, et al. Anesthesia-related cardiac arrest in children with heart disease: data from the Paediatric Perioperative Cardiac Arrest (POCA) registry. Anesth Analg. 2010;110(5):1376-82. https://doi. org/10.1213/ANE.0b013e3181c9f927.

4. Bergersen L, Gauvreau K, Foerster SR, et al. Catheterization for Congenital Heart Disease Adjustment for Risk Method (CHARM). JACC Cardiovasc Interv. 2011;4(9):1037-46. https://doi.org/10.1016/j.jcin.2011.05.021.

5. Jayaram N, Spertus JA, Kennedy KF, et al. Modeling major adverse outcomes of pediatric and adult patients with congenital heart disease undergoing cardiac catheterization: observations from the NCDR IMPACT Registry (National Cardiovascular Data Registry Improving Pediatric and Adult Congenital Treatment). Circulation. 2017;136:2009-19. https://doi.org/10.1161/ CIRCULATIONAHA.117.027714.

6. Nykanen DG, Forbes TJ, Du W, et al. CRISP: Catheterization RISk score fo pediatrics: A report from the Congenital Cardiac Interventional Study Consortium (CCISC). Catheter Cardiovasc Interv. 2016;87(2):302-9. https://doi. org/10.1002/ccd.26300.

7. Odegard KC, Vincent R, Baijal R, et al. SCAI/CCAS/SPA expert consensus statement for anesthesia and sedation practice: Recommendations for patients undergoing diagnostic and therapeutic procedures in the pediatric and congenital cardiac catheterization laboratory. Catheter Cardiovasc Interv. 2016;88:912-22. https://doi.org/10.1002/ccd.26692.

8. Feltes TF, Bacha E, Beekman RH III, et al; on behalf of the American Heart Association Congenital Cardiac Defects Committee of the Council on Cardiovascular Disease in the Young, Council on Clinical Cardiology, and Council on Cardiovascular Radiology and Intervention. Indications for cardiac catheterization and intervention in pediatric cardiac disease: a scientific statement from the American Heart Association. Circulation. 2011;123:2607-52. https://doi.org/10.1161/CIR.0b013e31821b1f10.

9. Lam JE, Lin EP, Alexy R, Aronson LA. Anesthesia and the pediatric cardiac catheterization suite: a review. Pediatr Anesth. 2015;25(2):127-34. https://doi. org/10.1111/pan.12551.

10. Hascoët $S$, Warin-Fresse $K$, Baruteau AE, et al. Cardiac imaging of congenita heart diseases during interventional procedures continues to evolve: Pros and cons of the main techniques. Arch Cardiovasc Dis. 2016;109(2):128-42. https:// doi.org/10.1016/j.acvd.2015.11.011.

11. Fagan TE, Truong UT, Jone P-N, et al. Multimodality 3-dimensional image integration for congenital cardiac catheterization. Methodist Debakey Cardiovasc J. 2014;10(2):68-76. https://doi.org/10.14797\%2Fmdcj-10-2-68.

12. Daaboul DG, DiNardo JA, Nasr VG. Anesthesia for high-risk procedures in the catheterization laboratory. Pediatr Anesth. 2019;29(5):491-8. https://doi. org/10.1111/pan.13571.

13. Deutsch N, Swink J, Matisoff AJ, et al. Anesthetic considerations for magnetic resonance imaging-guided right-heart catheterization in pediatric patients: A single institution experience. Pediatr Anesth. 2019;29(1):8-15. https://doi. org/10.1111/pan.13512 